\title{
SOBRE HOMINIZACIÓN Y HUMANIZACIÓN
}

\author{
Ángel Sánchez-Palencia Martí \\ Universidad Francisco de Vitoria. Madrid
}

\begin{abstract}
Resumen: El presente texto establece las relaciones entre el libro del Prof. Rodríguez Valls y la línea de investigación que su autor viene desarrollando desde el año 2014 sobre el nacimiento de lo humano.

Palabras clave: Hominización, humanización, antropología filosófica.

On hominization and humanization.

Abstract: This text establishes the relationship between Prof. Rodríguez Valls' book and the line of research that the author has been developing since 1994 on the birth of the human.

Keywords: Hominization, humanization, philosophical anthropology.

Recibido: 30/09/2019. Aceptado: 15/11/2019.
\end{abstract}

\section{Introducción}

El presente trabajo tiene su origen en la XXVI Sesión del Seminario permanente bibliográfico organizado por AEDOS, Asociación para el Estudio de la Doctrina Social de la Iglesia, en colaboración con el IIES, Instituto de Investigaciones Económicas y Sociales Francisco de Vitoria, de la Universidad Francisco de Vitoria (Madrid), celebrada el 22 de junio de 2019, en torno a la obra del Profesor Francisco Rodríguez Valls, de la Universidad de Sevilla: Orígenes del hombre. La singularidad del ser humano, publicada en 2017 en Madrid en la Editorial Biblioteca Nueva.

El libro objeto de reflexión del Seminario constituye una notable contribución académica a la cuestión sobre los orígenes del hombre y su singularidad específica, cuestión acerca de la cual existe enorme confusión en el imaginario colectivo que procede, en buena medida, de las interpretaciones del hecho evolutivo desde presupuestos filosóficos no explícitos o ideológicosque subyacen en los diversos medios de difusión: revistas científicas, textos y material audiovisual de divulgación, etc. He valorado especialmente la honestidad intelectual del autor que declara y razona en 
la introducción los supuestos de su pensamiento; así como las virtudes morales e intelectuales y el rigor epistemológico propios de una obra científica que, en la materia que trata el autor, ofrecen claridad que disipa las tinieblas de la confusión. Justamente en el campo de juego que ilumina la obra, he querido compartir en este trabajo las hipótesis que dan cuerpo a una línea de investigación en la que vengo trabajando desde el año 2014, que espero contribuyan a la fecundidad de esta actividad.

En la citada obra — título, tema y contenido- se dan cita las tres grandes cuestiones que vertebran toda antropología: origen, naturaleza y fin de la existencia humana, pues estas tres cuestiones se presentan imbricadas entre sí de tal manera que de las conclusiones a las que llega el pensamiento humano en cada una de ellas se pueden deducir enunciados implícitos acerca de las otras dos; y más allá de la antropología, acerca de las demás disciplinas filosóficas sobre las que descansa el tratado acerca del hombre, como son la cosmología o filosofía de la naturaleza y la ontología. En efecto, la antropología responde a la pregunta: ¿qué es el hombre? A la que, en una primera aproximación podemos responder, como lo hace el Diccionario de la Real Academia Española, "ser animado racional"; es decir, un vivo, un animal racional, según ha sido considerado desde antiguo en la cultura europea (occidental). Un ser, el hombre, que, según se muestraa la experiencia común y sostiene Aristóteles (Acerca del alma) — que afirma la unidad de la doble vertiente orgánica y anímica; es decir, la unidad biopsíquica que presenta el ser humano-, en el que el carácter de ser vivo (todo lo que refiere a la física y a las ciencias biológicas) entra con pleno derecho como género en la definición (hombre), mientras que su racionalidad indica su distinción dentro de ese género. De ahí se desprende también la idea central de las antropologías biológicas que el hombre es un ser en cuya corporeidad, y no sólo en sus operaciones psíquicas, que denominamos superiores por no encontrarse en el resto del reino animal, (inteligencia y voluntad), se hace patente la presencia de la racionalidad (o del espíritu). 
En este trabajo e intervención en el citado XXVI Seminario bibliográfico deseo exponer brevemente a la comunidad científica,congregada por el Seminario y a través de la presente publicación en la revista Naturaleza y Libertad, el planteamiento epistemológico, hipótesis y conclusiones provisionales que constituyen la materia del estudio interdisciplinar de la línea de investigación en paleoantropología realizadadesde hace algunos años junto al Profesor Rafael Jordana, de la Universidad de Navarra, en el seno delInstituto de Investigaciones Económicas y Sociales (IIES) Francisco de Vitoria. Se trata de una aproximación al objeto material de la antropología (el hombre) a través de la vía ascendente, que parte de las conclusiones de las ciencias de la naturaleza y las ciencias humanas (aquellas que estudian la acción humana considerada sectorialmente) para adentrarse en la filosofía (metafísica) a través de la cosmología (en el caso de las ciencias de la naturaleza) hacia la antropología. No obstante, importa señalar que dicha vía ascendente no olvida que la antropología filosófica es, en su radicalidad, filosofía primera o metafísica; no una filosofía segunda. No es posible en efecto, enfrentarse con el principio y fin del hombre, en su integridad, sino en cuanto brota, constituyéndose como persona, de la Palabra creadora de Dios; es decir, en la perspectiva trascendental propia de la filosofía primera.

\section{El hombre entre los vivos}

La constatación de que el hombre es uno entre los seres vivos, un ser en continuidad con la naturaleza, sitúa la pregunta antropológica en el objeto material y formal de la cosmología, en concreto en el campo de la pregunta ¿qué es la vida?, que no es una pregunta biológica sino filosófica. No es lo mismo existir que vivir. Todo cuanto vive existe, mas no todo cuanto existe vive. En realidad, la vida es un concepto abstracto tomado del verbo vivir. Es sabido que la reflexión filosófica acerca de la vida gira en torno a dos concepciones: mecanicismo y vitalismo. Para las doctrinas mecanicistas el ser vivo no sería otra cosa que una máquina más perfecta. Entre los seres vivos e inertes no existirían diferencias esenciales o cualitativas, 
Ángel Sánchez-Palencia

sino accidentales o de cantidad. Por su parte, el vitalismo sostiene que entre los seres naturales los hay vivos y no vivos, y que entre ellos existe una diferencia ontológica.

En el maravilloso universo creado encontramos tres acontecimientos que desafían permanentemente a la inteligencia humana; a saber, el origen del propio universo, el origen de la vida y el origen de la vida inteligente. En el hombre (microcosmos, según expresión de Demócrito)se dan cita estos tres modos de ser: physis, bios y psiqué; de modo que la inquisición filosófica sobre el vivo humano alcanza también el ámbito de la paleontología que estudia los seres vivos desaparecidos a través de sus restos fósiles con el auxilio de las ciencias biológicas y geológicas, tratando de descubrir las relaciones de parentesco y descendencia de unas especies respecto a otras hasta explicar la biodiversidad o diversidad específica actual, habida cuenta de la evidencia de la evolución biológica. En efecto, la evolución biológica es un hecho que se deduce a partir de observaciones del mundo natural que no pueden comprenderse más que por la relación de descendencia y parentesco de unas especies con otras anteriores desde un hipotético primer organismo que denominamos LUCA (Last Unknown Common Ancestor). Se trata de un conocimiento que tiene que ver con la observación y con el pensamiento lógico-deductivo y por tanto no pertenece a la ciencia experimental, es una filosofía natural. Cuestión distinta es la teoría o teorías de la evolución. Una teoría es una elaboración metacientífica, distinta de los datos procedentes de la observación, que es homogénea con la facticidad descrita que relaciona e interpreta esos hechos diferentes en una explicación unitaria. En el caso de la evolución y singularmente de la evolución humana (paleoantropología), encontramos una pluralidad de teorías que afectan, de una parte, a la diversidad de explicaciones propuestas respecto a los mecanismos a través de los cuales se verifica la evolución; de otra, a las diversas filosofías que inspiran la lectura e interpretación de la facticidad científica. A este respecto, lo que encontramos en buena parte de la literatura científica de divulgación e implícitamente en parte de la literatura científica, y en lo que podríamos llamar literatura pseudocientífica, por la 
Sobre hominización y humanización

ilegitimidad que supone presentar como enunciados científicos lo que, en realidad, son lecturas metacientíficas muchas veces de carácter ideológico.

\section{La paleoantropología y su interpretación: indagando en los orígenes}

Frente a ello, la cuestión del origen del hombre requiere de un pensamiento en suspensión que considere a la vez diversas ciencias, de una parte, las ciencias que estudian la facticidad; de otra el juicio metacientífico compete propiamente a las ciencias filosóficas (antropología, cosmología y ontología) y, luego, en diálogo con la razón natural, a la teología o ciencia de la fe. Respecto a la facticidad disponemos de dos vías principales: el registro fósil y el registro arqueológico; ambos son incompletos y fragmentarios, especialmente el primero, lo cual debe hacernos mantener una actitud cauta y humilde respecto a nuestras especulaciones intelectuales interpretativas.

Como toda indagación científica, y entendemos la ciencia en sentido amplio como conocimiento cierto por causas, que incluye a la filosofía que es ciencia de las causas últimas, partimos en nuestra indagación de la observación y enumeración de la singularidad del hombre actual (Homo sapiens). Dentro de las características específicas de Homo sapiens están descritas las apomorfias o rasgos evolutivamente novedosos que muestran la singularidad de la especie humana por respecto a otras especies animales. Entre ellas, podemos señalar los siguientes rasgos que distinguen a los humanos de los simios: a) anatómicos: la forma del cuerpo y tórax, las propiedades craneales (caja craneal y cara), tamaño relativo del cerebro, longitud relativa de las extremidades, larga ontogenia y tiempo de vida, caninos pequeños, pulgar alargado y dedos acortados, presencia de una barbilla, cráneo equilibrado en lo alto de la columna vertebral, dimensiones de la pelvis y espina dorsal en forma de S. Las tres últimas directamente relacionadas con la más notable singularidad anatomo-morfológica del hombre: la bipedestación. Otras dos características anatómicas que no se reflejan en los fósiles son la topología del cerebro y el vello corporal reducido. b) funcionales: lenguaje 
Ángel Sánchez-Palencia

y construcción avanzada de herramientas (Carroll: 2003). Este es el fenómeno que hemos de explicar cabalmente: la singularidad de Homo sapiens hoy en el largo camino evolutivo del género Homo.

\section{Las fuentes}

Como señalábamos más arriba, disponemos de tres tipos de fuentes científicas que iluminan la teorización evolutiva del fenómeno. En primer lugar, la ordenación taxonómica del objeto y los hechos: el registro fósil y arqueológico. La taxonomía (del gr. táxis, ordenación y -nomía) es la ciencia que trata de los principios, métodos y fines de la clasificación. En biología, se aplica para la ordenación jerarquizada y sistemática, con sus nombres, de los grupos de vivientes y en paleoantropología para clasificar los hallazgos fósiles. Así, Homo sapiens es ordenado en las siguientes categorías taxonómicas: Reino: Metazoos; Filum: Cordados; Clase: Mamíferos; Orden: Primates; Superfamilia: Hominoidea; Familia: Hominidae; Subfamilia: Homininae; Tribu: Hominini; Género: Homo; Especie: Homo sapiens. Por lo que respecta al registro fósil, en la tabla a continuación (Jordana: 2016) encontramos las siguientes especies descritas (Denominación binomial linneana, autor, año de descubrimiento y datación aproximada):

Homo sapiens Linné 1758

$0.00-0.2 \mathrm{Ma}$

Homo floresiensis Brown et al., 2004

$0.02-0.09 \mathrm{Ma}$

Homo neanderthalensis King, 1864

$0.03-0.5 \mathrm{Ma}$

Denisovan 2012

$0.03-0.5 \mathrm{Ma}$

Homo heidelbergensis Schoetensack 1908, 1971

$0.2-0.7 \mathrm{Ma}$

Homo naledi Berger et al., 2015

$0,3 \mathrm{Ma}$

Homo antecessor Bermúdez de Castro et al., 1997

(H. erectus europeo)

$0.8-1.3 \mathrm{Ma}$

Homo erectus (Dubois, 1891) 1891, 1929, 1937, 1960, 1969 0.3-1.8 Ma

Homo ergaster Groves and Mazak 1975, 1984 (H. Ere. africano) $1.8 \mathrm{Ma}$

Homo georgicus Gabunia et al., 2002 (H. habilis europeo) $\quad 1.8 \mathrm{Ma}$ 
Homo habilis Leakey et al., 1964, 1968, 1973, 1976, 1995 1.1-1.9 Ma

Homo rudolfensis (Alexeev, 1986) 1972, 1986, $2012 \quad$ 1.4-2.4 Ma

Homo sp de Afar, 2015* $3 \mathrm{Ma}$

Homo? (Kenianthropus) platyops Leakey et al., $2001 \quad 3.2-3.5 \mathrm{Ma}$

Paranthropus boisei, Leakey, 1959, 1970, $1993 \quad 1.1-2.1 \mathrm{Ma}$

Paranthropus robustus Broom, 1938, 1950, $1994 \quad 1.5-2 \mathrm{Ma}$

Paranthropus aethiopicus (Arambourg, 1968) (Olson,1985) 2.3-2.6 Ma

Australopithecus sediba Berger, 2010, $2013 \quad 2.4-3 \mathrm{Ma}$

Australopithecus garhi Asfaw, $1999 \quad 2.5 \mathrm{Ma}$

Australopithecus africanus Dart, 1925, $1936 \quad 2-3 \mathrm{Ma}$

Australopithecus bahrelghazali Brunet, $1993 \quad 3-3.5 \mathrm{Ma}$

Australopithecus afarensis Johanson\& Taieb 1975 3-3.5 Ma

Australopithecus deyiremeda Haile-Selassie et al., 2015* 3-3.5 Ma

Australopithecus anamensis Leakey 1995

Ardipithecus ramidus White et al, 1994, $2009 \quad 4.5 \mathrm{Ma}$

Ardipithecus kadabba Haile-Selassie, 2001

Orrorin tugenensis Pickford \&Senut, $2000 \quad 6 \mathrm{Ma}$

Sahelanthropus tchadensis Brunet et al., $2002 \quad 6.7 \mathrm{Ma}$

Por lo que respecta a los hallazgos arqueológicos, habida cuenta del fin del presente trabajo, basta señalar que lasevidencias arqueológicas de industria lítica y fabricación de utensilios más remotas datan de aprox. 3.3 millones de años (Lomekwian technology). La tecnología Lomekwianana recibe su nombre del sitio arqueológico de Lomekwi, cerca de la ribera oeste del lago Turkana (Kenia). A lo largo del paleolítico bajo, medio y alto, se suceden y solapan en algunos casos las culturas Oldowaniana, Achelense, Mousteriense, Chatelperroniense, Auriñaciense, Gravetiense, Salutrense y Magdaleniense. Más allá de su evolución, la techné es acumulativa, la cultura lítica considerada en general muestra inequívocamente una conducta técnica. 
Ángel Sánchez-Palencia

En segundo lugar, consideramos las fuentes filosóficas. El diálogo con la ciencia precisa un aparato conceptual metafísico que permita una interpretación adecuada de la facticidad descrita. En este sentido, de entre la dogmática antropológica disponible, estimamos que la tradición aristotélico-tomista es especialmente apta por varios motivos. Desde el punto de vista epistemológico por la relevancia que adquiere la somatología en la concepción del hombre de Aristóteles y Tomás de Aquino; desde el punto de vista metafísico, por su visión sintética de la substancia (hilemorfismo), especialmente en la explicación de los vivos, frente a la doctrina monista que reduce todo a la materia y a la doctrina dualista que separa lo material de lo psíquico-espiritual. Y, por último, desde el punto de vista ontológico (ya habíamos dicho que la antropología filosófica descansa sobre la cosmología que, a su vez, se apoya en la ontología) encontramos, dicho sea de manera muy esquemática, tal vez demasiado, las dos grandes concepciones: materialismo y teísmo que ven, respectivamente, en la materia o en la inteligencia el principio explicativo último del universo.

En tercer lugar, señalamos los principales enunciados derivados de la profesión de fe de la Iglesia Católica en orden a establecer un diálogo entre fe y razón en el ámbito de la propuesta del Papa Benedicto XVI de ensanchar los horizontes de la razón. Consideramos dos enunciados fundamentales: la noción de imago Dei, el hombre ha sido creado a imagen y semejanza de Dios (Gn, 1, 26); y la afirmación de Pio XII en Humani generis que el cuerpo humano tiene su origen en la materia viva que existe antes que él, pero el alma espiritual es creada inmediatamente por Dios («animas enim a Deo immediate creari católica fides nos retinere iubet»).

\section{La lectura de las fuentes}

La teorización acerca de la cuestión que nos ocupa: el origen del hombre y la evolución de nuestra especie, indaga en las causas que pueden dar razón de los hechos, aparentemente inconexos entre sí. Mas para descubrir un entramado causal conviene tener muy presente a Sócrates, que marca muy 
bien la diferencia entre causa y condición material cuando en Fedón, dice a sus discípulos por qué con sus miembros nose han encaminado hacia Mégara o Beocia,

\footnotetext{
...arrastrados por la esperanza de lo mejor, si no hubiera creído que es más justo y más noble soportar la pena que la ciudad ordena [...] Pero llamar causas a las cosas de esa clase es demasiado absurdo. Si uno dijera que sin tener cosas semejantes, es decir, tendones y huesos y todo lo demás que tengo, no sería capaz de hacer lo que decido, diría cosas ciertas. Sin embargo, decir que hago lo que hago a causa de ellas [...] sería un enorme y excesivo abuso de expresión. Pues eso es no ser capaz de distinguir que una cosa es lo que es la causa de las cosas y otra aquello sin lo cual la causa no podría nunca ser causa. A esto me parece que los muchos que andan a tientas como en tinieblas, adoptando un nombre incorrecto, lo denominan como causa $(99 \mathrm{a}, \mathrm{b})$.
}

Las hipótesis que manejamos en la citada línea de investigación con el Profesor Jordana, y que estimo pueden contribuir a una lectura fecunda de la obra del Profesor Rodríguez Valls y al diálogo interdisciplinar, podemos resumirlas en las siguientes:

En primer lugar, que el registro fósil del género Homo, a pesar de utilizar la nomenclatura binomial linneana, puede referir más bien que especies biológicas, como frecuentemente es interpretado, morfoespecies que ponen de manifiesto una gran variabilidad morfológica dentro de una sola especie humana en el sentido metafísico del término; es decir, la esencia considerada como principio de la diversidad específica del universo.

En segundo lugar, por lo que respecta al registro arqueológico y en apoyo de la hipótesis anterior, hemos considerado que la cultura lítica muestra inequívocamente una conducta técnica, que no debemos confundir con la conducta instrumental, que ciertamente encontramos en el mundo animal. ¿Qué es una conducta técnica?, ¿̇uáles son sus características y cuáles los presupuestos gnoseológicos implícitos en ella? La conducta técnica consiste en la fabricación de herramientas; es decir, en la transformación de una determinada materia, adecuada por sus propiedades, conforme a una idea ejemplar concebida en la mente, ordenada a un determinado fin. Por primitiva que sea la industria lítica, en sí misma, supone un conocimiento 
conceptual propio de la inteligencia humana, un comportamiento cualitativamente distinto del comportamiento animal.

En tercer lugar, siguiendo el principio "agere sequitur ese", el actuar sigue al ser, y como explicación antropológica de lo dicho en segundo lugar, la doctrina tomista del alma espiritual que según su esencia es forma de lo corporal y no algo añadido, explica que la materia en los actos del entendimiento es condición porque concurre en ellos de una manera extrínseca e indirecta, y que el genuino acto del entendimiento humano es la abstracción de la esencia y su representación mental en forma de concepto.

La presencia de esa dimensión espiritual marcaría el inicio de la existencia del hombre, que se produce en un momento que no podemos fijar con exactitud en el proceso evolutivo. Habría que aceptar, además, la existencia de una cierta "infancia” del hombre, en la que las características humanas, aunque ya presentes, no están del todo desarrolladas (Udías: 2010).

El hombre así considerado estaría en continuidad física con el universo material y en discontinuidad ontológica. El paso a lo espiritual no es obviamente objeto de observación científica; sin embargo, puede descubrir una serie de indicios muy valiosos de la singularidad de la especie humana.

\section{Una hipótesis alternativa}

Llegamos así a la conclusión que da título a este trabajo. En la mayor parte de literatura sobre la cuestión de los orígenes a la que hemos tenido acceso, la teoría dominante para explicar la mente humana es el emergentismo: "m. Teoría que, en su faceta antropológica, atribuye la inteligencia, la voluntad y los fenómenos psíquicos a una acumulación de fenómenos neuronales, analizables exclusivamente con el método científico hipotético-deductivo. Consecuentemente, deduce que nuestra ignorancia científica sobre el psiquismo humano es simple falta de desarrollo de nuestros conocimientos neurofisiológicos. La filosofía analítica ha vuelto a 
demostrar recientemente lo que ya defendió la filosofía clásica: los fenómenos psíquicos son irreductibles a lo orgánico o material." (Diccionario médico, $\mathrm{CUN}^{1}$ ).El emergentismo lleva consigo una concepción ontológica materialista: la materia es el fundamento de todo lo existente, y todos los demás modos de ser, incluidas las singularidades humanasemergen de procesos materiales que, como tales, son inconscientes y ateleológicos.

Frente a la hipótesis emergentista según la cual la hominización es anterior y causa de la humanización en el proceso evolutivo, podemos pensar de otra manera y plantear una hipótesis alternativa que denominamos creacionista-evolutiva:

El proceso paulatino de especialización del hombre —su hominización-, es posterior a su humanización: lo primero es ser hombre, y después su variación morfológica, que se especializa seleccionando los cambios morfológicos y funcionales (aleatorios), que permiten una mejor expresión de su ser espiritual. Es el alma humana quien gobierna pasivamente —utilizando los mismos medios de la selección natural— el propio destino morfológico del hombre hasta llegar a su plenitud de expresión [...] La mejor adaptación al espíritu supone, al contrario de lo que sucede en el reino animal, una desespecialización morfológica. El dominio que ejerce el espíritu y la posibilidad de utilizar instrumentos, independiza al hombre con respecto al medio: no necesita adaptarse morfológicamente [...] el hombre adapta el medio a sus necesidades (Jordana: 1988).

El creacionismo evolutivo lleva consigo una concepción ontológica teísta: la realidad primera es una mente que diseña y actúa. El universo es creado y, como tal, un acto libre, querido, ordenado a una causa final. Es una obra consciente, y no un producto del azar.

\section{Ángel Sánchez-Palencia Martí a.s.palencia@ufv.es}

